\title{
COTAS UNIVERSITÁRIAS NO BRASIL: UMA ANÁLISE SOBRE O COMPORTAMENTO INSTITUCIONAL ${ }^{1}$
}

\author{
UNIVERSITY QUOTAS IN BRAZIL: \\ AN ANALYSIS OF THE INSTITUTIONAL BEHAVIOR
}

\author{
Carlos Bolonha* \\ Chiara de Teffé**
}

\begin{abstract}
RESUMO: O presente estudo analisa o comportamento institucional brasileiro no trato do tema das cotas universitárias. Este assunto apresenta a sua relevância, uma vez que envolve uma seleção de vagas destinada a pessoas que se enquadram em determinados critérios de etnia, raça, gênero ou condição socioeconômica, o que gera, consequentemente, uma grande controvérsia na sociedade. Estuda-se a possível ausência de uniformidade nas reservas de vagas estabelecidas nos editais dos vestibulares, em nível nacional, e a vulnerabilidade no diálogo entre as instituições brasileiras. Partese da hipótese de que uma rede de diálogos entre os Poderes do Estado e as universidades públicas representa um importante instrumento para que o sistema de cotas universitárias seja concretizado de forma legítima e eficaz, respeitando-se o princípio da igualdade material.
\end{abstract}

PALAVRAS-CHAVE: Cotas universitárias. Princípio da igualdade. Diálogo institucional.

ABSTRACT: The present study analyzes the Brazilian institutional behavior regarding the university quotas system. This issue is relevant, because involves a preferential selection on the basis of race, gender, socio-economic conditions or ethnicity, generating an intense controversy. This study presents the possible absence of uniformity on the criteria established in the admission announcements and the vulnerability in the dialogue among Brazilian institutions. We start from the assumption that a network of dialogs among the three branches of government and public universities is an important instrument to implement the university quota system in a legitimate and effective way, while respecting the principle of substantive equality.

KEYWORDS: University Quotas. Equality Principle. Institutional Dialogue.

* Professor Adjunto da Graduação e da Pós-Graduação da Faculdade de Direito da Universidade Federal do Rio de Janeiro. Professor Orientador no Mestrado. Doutorado em Teoria do Estado e Direito Constitucional pela Pontifícia Universidade Católica do Rio de Janeiro. Rio de Janeiro (RJ). E-mail: bolonhacarlos@gmail.com.

** Graduando em Direito pela Universidade Federal do Rio de Janeiro. Bolsista de Iniciação Científica (IC -FAPERJ) e pesquisadora dos Projetos acima descritos. Rio de Janeiro (RJ). Email: chideteffe@hotmail.com

1 Este artigo foi elaborado no âmbito do Grupo de Pesquisa “A questão de cotas no Brasil: diálogos institucionais e fundamentos constitucionais-democráticos" (pesquisa ganhadora do prêmio de melhor trabalho na Jornada de iniciação científica do CCJE-UFRJ de 2011) e do Laboratório de Estudos Teóricos e Analíticos sobre o Comportamento das Instituições (LETACI), vinculado à Faculdade Nacional de Direito e ao Programa de PósGraduação em Direito da Universidade Federal do Rio de Janeiro, com financiamento da Fundação Carlos Chagas Filho de Amparo à Pesquisa do Estado do Rio de Janeiro (FAPERJ) pela concorrência do Edital n. ${ }^{0} 9$ de 2011 (Processo n. ${ }^{\circ}$ E-26/111.832/2011) e do Conselho Nacional de Desenvolvimento Científico e Tecnológico (CNPq) pela concorrência do Edital Universal de 14/2011 (Processo n. ${ }^{\circ}$ 480729/2011-5). 
"O que não se admite é a desigualdade no ponto de partida, que assegura tudo a alguns, desde a melhor condição econômica até o melhor preparo intelectual, negando tudo a outros, mantendo os primeiros em situação de privilégio, mesmo que sejam socialmente inúteis ou negativos".

(DALLARI, 309)

\section{INTRODUÇ̃̃̃O}

Pode-se afirmar que o tema das cotas universitárias tem a sua importância centrada na própria formação da cidadania brasileira. Entende-se que este instrumento de ação afirmativa se apresenta como um mecanismo essencial para trazer uma real efetividade ao direito fundamental à educação e ao princípio da igualdade, visto que objetiva diminuir significativamente o preconceito e a discriminação racial e social, inserindo determinados grupos que ainda representam um número pouco expressivo dentre aqueles que cursam o ensino superior em instituições públicas ${ }^{2}$. Diante de tal perspectiva, há uma tendência nacional, por parte das universidades, em adotar o sistema de cotas para as suas vagas de ingresso na graduação.

Um dos principais instrumentos para que se promova de forma eficaz a adoção de reservas de vagas com critérios sensíveis à raça ${ }^{3}$ e à condição socioeconômica ${ }^{4}$,

2 Pesquisas apontam para o fato de que estudantes pobres negros e pobres brancos ainda não se encontram nas mesmas condições, uma vez que, aqueles ainda permanecem sob um duplo julgamento, em razão de suas condições socioeconômicas e raciais. Conforme dados obtidos pelo IBGE, a proporção de cidadãos entre idades de 18 e 24 anos que cursaram o ensino superior mostrou uma situação, em 2009, inferior para os negros e para os pardos, em relação à situação dos brancos, em 1999. Enquanto cerca de $2 / 3$, ou 62,6\%, dos cidadãos brancos estão estudando em 2009, os dados mostram que há menos de 1/3 para os outros dois grupos: 28,2\% dos cidadãos negros e 31,8\% dos pardos. IBGE. Síntese de Indicadores Sociais - Uma Análise das Condições de Vida da População Brasileira 2010, p. 227-228.

3 A utilização do termo "raças", como critério diferenciador, não é pacífica. Todavia, nos editais universitários e nas leis referentes ao tema, verificou-se a larga utilização deste conceito. Nos últimos anos, quanto à abrangência do conceito de "raça", o Supremo Tribunal Federal vem se posicionando de acordo com o precedente criado no acórdão do HC 82424, em que se entendeu: "3. Raça humana. Subdivisão. Inexistência. Com a definição e o mapeamento do genoma humano, cientificamente não existem distinções entre os homens, seja pela segmentação da pele, formato dos olhos, altura, pêlos ou por quaisquer outras características físicas, visto que todos se qualificam como espécie humana. Não há diferenças biológicas entre os seres humanos. Na essência são todos iguais. 4. Raça e racismo. A divisão dos seres humanos em raças resulta de um processo de conteúdo meramente político-social. Desse pressuposto origina-se o racismo que, por sua vez, gera a discriminação e o preconceito segregacionista". A jurista Daniela Ikawa leciona que: "O uso do termo raça é justificável nas políticas afirmativas (...) por ser o mesmo instrumento de categorização utilizado para a construção de hierarquias morais convencionais não condizentes com o conceito de ser humano dotado de valor intrínseco ou com o princípio de igualdade de respeito (...). Se a raça foi utilizada para construir hierarquias, deverá também ser utilizada para desconstruí-las. Trata-se de um processo de três diferentes fases: i. a construção histórica de hierarquias convencionais que inferiorizaram o indivíduo quanto ao status econômico e de reconhecimento pela mera pertença a determinada raça (...); ii. a reestruturação dessas hierarquias com base em políticas afirmativas que considerem a raça, voltando-se agora à consolidação do princípio de dignidade; iii. A descaracterização do critério raça como critério de inferiorização e o estabelecimento de políticas universalistas materiais apenas" (IKAWA, 2008b, p. 105-106.)

4 O jurista norte-americano utiliza-se desta expressão como sinônimo para o sistema de cotas nas universidades e faculdades dos EUA. (DWORKIN 2005b, p. 543). 
garantindo-se a existência de cidadãos livres e iguais, é a defesa de um sistema de $\operatorname{cotas}^{5}$ construído a partir da seguinte premissa: a efetividade das cotas universitárias, em âmbito nacional, depende em grande parte, de uma análise minuciosa do comportamento institucional e da promoção de seu diálogo, produzindo-se uma diretriz harmônica que, realmente, contemple e inclua minorias e determinados segmentos no ensino superior e público. Dessa forma, pretende-se neste estudo, por meio de um enfoque essencialmente jurídico $^{6}$, abordar as cotas universitárias e a sua relação com o princípio da igualdade e, posteriormente, analisar criticamente o posicionamento dos três poderes do Estado e das instituições de ensino ante o sistema de cotas, destacando possíveis divergências e a forma como ocorre ou não um possível diálogo institucional.

A metodologia adotada divide-se em três etapas. Na primeira, buscou-se analisar os editais das universidades públicas, por meio de seu mapeamento e posterior confecção de tabelas indicando o ano, critério adotado e quantidade de reserva. Na segunda, a jurisprudência dos principais tribunais e a legislação federal e estadual pertinentes foram amplamente estudadas, destacando-se confrontos, divergências, base argumentativa e posicionamento diante do tema. Além disso, verificaram-se os programas e as políticas que o Executivo federal vem promovendo nos últimos 10 anos, aproximadamente. Por fim, realizou-se um trabalho crítico com o material levantado, visando extrair conclusões que possam contribuir de alguma forma para o desenvolvimento do objeto pesquisado.

O método utilizado na pesquisa foi, essencialmente, de natureza dedutivo-analítica. Sob o aspecto material, foi realizado o levantamento de bibliografia, editais, jurisprudência, legislação federal e estadual e políticas desenvolvidas pelo Executivo. Quanto ao aspecto temporal, o estudo do sistema de cotas universitárias das instituições públicas brasileiras foi delimitado da seguinte forma: a legislação, a partir do ano de 1999; os editais entre 2009 e $2012^{7}$; a jurisprudência entre os anos de 2003 e 2012.

5 Considera-se um sistema de cotas o conjunto de normas que representam, dentro de uma política de admissão na universidade, o tratamento diferenciado para fins de promoção de igualdade, abrangendo (I) normas que definem qual a espécie de ação afirmativa adotada; (II) normas que indicam a natureza da distinção; (III) normas que determinam o quantum estabelecido para a distinção; e (IV) normas que determinam os meios da universidade acompanhar o candidato beneficiado ao longo de seu curso e (ou) seu egresso em sua atuação profissional posteriormente à formação universitária.

6 Entende-se que a análise integral do tema das cotas universitárias necessita de um estudo interdisciplinar com as diversas áreas das ciências humanas. Todavia, em razão da especificidade do recorte temático proposto, o assunto será trabalhado principalmente sob a óptica do Direito e, quando necessário, serão mencionadas referências da sociologia, filosofia e das ciências políticas.

7 Salvo em relação à universidade estadual do Rio de Janeiro (UERJ), em que se analisou a trajetória das cotas na referida instituição desde a sua implantação, em 2003. 


\section{AS AÇÕES AFIRMATIVAS E AS COTAS UNIVERSITÁRIAS}

As ações afirmativas representam um importante meio de inclusão dos cidadãos que, em razão de um processo histórico de discriminação da pobreza e da origem racial, encontram-se de certa forma ainda marginalizados na sociedade. Promovem a diversidade nos ambientes de trabalho e ensino, além de representarem a criação de modelos positivos para os estudantes e as populações minoritárias. Conforme ensina Joaquim Barbosa Gomes (2001, p. 129-152), as ações afirmativas:

podem ser definidas como um conjunto de políticas públicas e privadas de caráter compulsório, facultativo ou voluntário, concebidas com vistas ao combate à discriminação racial, de gênero, por deficiência física e de origem nacional, bem como para corrigir ou mitigar os efeitos presentes da discriminação praticada no passado, tendo por objetivo a concretização do ideal de efetiva igualdade de acesso a bens fundamentais como a educação e o emprego.

Como uma das espécies de ações afirmativas, as cotas atuam como um importante instrumento para o processo de amadurecimento global na construção dos conceitos de democracia e cidadania, além de representar um meio veloz de transformação, sobretudo, no domínio da mobilidade socioeconômica. (MUNANGA, 2002) ${ }^{8}$ No âmbito das universidades, as cotas sociais e raciais significam a efetivação de uma discriminação positiva, capaz de ampliar a diversidade cultural, racial e social nas instituições de ensino. Mais ainda, entende-se que, em longo prazo, elas seriam responsáveis por mudar substancialmente a composição daqueles que ingressam na universidade pública, tanto no corpo discente quanto docente, ajudando a suprimir possíveis estereótipos ou hostilidades na vida universitária e no convívio geral da comunidade9 .

Neste sentido, embasadas pelo princípio constitucional da Autonomia Universitária ${ }^{10}$ e influenciadas pelo histórico das ações afirmativas nos Estados Unidos, as universidades públicas brasileiras vêm se posicionando favoravelmente à adoção de diretrizes de admissão sensíveis à raça e à condição financeira do cidadão. Demonstram, portanto, que têm consciência de sua função integradora e de sua responsabilidade pública,

8 Texto apresentado na IX Semana de Ciências Sociais da UFG, de 4 a 8 de novembro de 2002, a convite do Projeto Passagem do Meio: Qualificação de Alunos(as) Negros(as) de Graduação para Pesquisa Acadêmica na UFG/LPP-UERJ/Fundação Ford.

9 “O significado político-simbólico das medidas de ação afirmativa é obvio. Enquanto outros tipos de política anti-racista adotados até então (promoção da cultura afro-brasileira, leis anti-racistas etc.) apresentavam-se como corretivos do modelo estabelecido, sem confrontar diretamente o discurso da mestiçagem tolerante, as políticas de ação afirmativa implicam admitir que afrodescendentes foram sistematicamente desfavorecidos, e mais, implicam o reconhecimento de que não há saída possível para combater o racismo no interior da gramática que apresenta a nação como "cadinho de raças". "(COSTA, 2006, p. 150)

${ }^{10}$ Conforme o artigo 207 da Constituição da República Federativa do Brasil de 1988: "As universidades gozam de autonomia didático-científica, administrativa e de gestão financeira e patrimonial, e obedecerão ao princípio de indissociabilidade entre ensino, pesquisa e extensão". 
escolhendo metas que beneficiam uma comunidade muito mais ampla do que seus próprios corpos docente e discente; visam a "melhorar a vida da comunidade, não só protegendo a sua cultura e sua ciência, ou aperfeiçoando a medicina, o comércio e a agricultura, mas ajudando a tornar essa vida coletiva mais justa e harmoniosa" (DWORKIN, 2005b, p. 572).

A partir dessa concepção, até o momento, pelo menos 56 instituições públicas já fazem uso de tal ação afirmativa, traçando e delimitando internamente o sistema de cotas que irá adotar, seja por lei, seja por resolução universitária. Esta forma de deliberação será ao longo do trabalho melhor compreendida por meio de uma análise institucional. Todavia, inicialmente, vale ressaltar que se vive com a ausência de uma diretriz, em âmbito nacional, que estabeleça a possibilidade da reserva de vagas, a sua quantidade e a sua espécie.

\section{AS Cotas UniVersitárias E A SUA RELAÇão COM O PRINCíPIO DA IGUALDADE MATERIAL}

O princípio da igualdade encontra-se positivado no artigo $5^{\circ}$, caput, da Constituição Federal, constando no rol de suas cláusulas pétreas. O legislador originário constituinte estabeleceu que "todos são iguais perante a lei, sem distinção de qualquer natureza". No ordenamento jurídico brasileiro, tanto a doutrina quanto a jurisprudência vêm se debruçando de forma minuciosa no desenvolvimento da real compreensão do conteúdo jurídico da igualdade. Para isso, trabalha-se massivamente com autores europeus e norte-americanos, partindo-se da bipartição do princípio em seus aspectos formal e material.

Em um primeiro momento, entendeu-se que a referida norma consagrava apenas o aspecto formal da igualdade, quando sob o manto do ideário liberal clássico rejeitavase a ideia de que as forças econômicas poderiam provocar desigualdades substanciais ou, pelo menos, não considerava que essas desigualdades socialmente provocadas deveriam ser amenizadas por qualquer forma de ação pública. A igualdade era assegurada pela Carta, mas não havia mecanismos capazes de garantir efetivamente tal direito.

O princípio da igualdade, como um valor meramente formal, há muito foi superado, por não se mostrar suficiente para orientar as sociedades plurais e multiculturais características do final do século XX. Pontua-se que a ideia de democracia, nos dias atuais, exige a superação de uma concepção mecânica, estratificada, da igualdade, a qual no passado era definida apenas como um direito, sem que se cogitasse, contudo, a sua conversão em uma real possibilidade ${ }^{11}$. Nesse contexto, o viés substancial ou material deste princípio garante uma atuação transformadora, promovendo possíveis

\footnotetext{
${ }^{11}$ Brasil. Supremo Tribunal Federal. ADPF n. ${ }^{\circ} 186$. Relator: min. Ricardo Lewandowski.
} 
modificações nas desigualdades sociais e raciais. (GOMES; DA SILVA, p. 86-153) Gilmar Mendes afirma que, diante do princípio da igualdade, cabe ao operador do direito interpretá-lo e delimitar os seus desdobramentos, conforme a óptica da fraternidade e da tolerância, uma vez que estas seriam responsáveis por impor nas sociedades multiculturais a igual consideração do outro em suas peculiaridades e idiossincrasias. ${ }^{12}$

Seguindo essa óptica, dentre os intrincados temas que são orientados pelo princípio da igualdade, as ações afirmativas têm despertado a maior polêmica, levantando uma série de embates doutrinários e conflitos entre decisões institucionais. Não obstante a falta de consenso, diante da previsão constitucional de tal princípio, nos últimos anos, abriu-se uma diversa gama de tratamentos positivos diferenciados, os quais vêm sendo adotados tanto por setores governamentais quanto por movimentos sociais, por meio de leis infraconstitucionais, políticas públicas e projetos. Objetiva-se, assim, a igualdade fática entre os cidadãos.

Conforme a jurisprudência do Supremo Tribunal Federal, o sentido mais elementar para o estabelecimento de ações afirmativas é encontrado na máxima tratar de forma desigual os desiguais, na exata medida de sua desigualdade ${ }^{13}$. Isso significa dizer que "a lei pode, sem violação do princípio da igualdade, distinguir situações, a fim de conferir a um tratamento diverso do que atribui a outra" ${ }^{14}$. Entretanto, convém observar que "o princípio isonômico revela a impossibilidade de desequiparações fortuitas ou injustificadas"15, devendo o operador do direito atender ao princípio da proporcionalidade fundamentado pela razoabilidade ${ }^{16}$ e aos demais valores constitucionais. Tal mecanismo representaria o melhor critério para aferir a juridicidade e a legitimidade das discriminações positivas

${ }^{12}$ Brasil. Supremo Tribunal Federal. ADPF n. ${ }^{\circ}$ 186. Relator: Min. Ricardo Lewandowski. Decisão do Ministro Gilmar Mendes, indeferindo o pedido de medida cautelar, ad referendum do Plenário, em 31 de julho de 2009.

${ }^{13}$ A ideia de "tratar igualmente os iguais e desigualmente os desiguais, na medida de suas desigualdades" já era apresentada por Aristóteles, mas, no Brasil, consagrou-se nas mãos do ilustre jurisconsulto Rui Barbosa. Avançando sobre a noção de tratar igualmente os indivíduos, conhecida como igualdade formal, que predominou a partir do fortalecimento do liberalismo com a classe burguesa alcançando o Poder Político. Representa a diretriz geral do conceito de igualdade material. Há quem se refira à frase como "a Máxima de Rui Barbosa".

${ }^{14}$ Brasil. Supremo Tribunal Federal. Tribunal Pleno. ADI n. ${ }^{o}$ 2.716. Relator: Min. Eros Grau. 2007.

15 Brasil. Supremo Tribunal Federal. AI. 207.130/SP. Relator: Min. Marco Aurélio. 1998.

${ }^{16}$ Como explica Barroso (2008, p. 241-246), o princípio da proporcionalidade se desdobra em três etapas procedimentais para averiguação da razoabilidade dos atos do poder público. Primeiro, "tem de haver racionalidade na desequiparação, vale dizer: adequação entre meio e fim”. Segundo, "a desequiparação, ademais, terá de ser necessária para a realização do objetivo visado, vedado o excesso, isto é, o tratamento diferenciado além do que é imprescindível”. Finalmente, "terá de haver proporcionalidade em sentido estrito. É imperativo que o valor promovido com a desequiparação seja mais relevante do que o que está sendo sacrificado". 
adotadas pela universidade ou pelo legislador, visto que estas partem de uma decisão política, mas que deve observar a supremacia das normas constitucionais ${ }^{17}$.

\section{O COMPORTAMENTO INSTITUCIONAL BRASILEIRO ANTE O SISTEMA DE COTAS UNIVERSITÁRIAS}

O estudo das teorias dialógicas nos remete às relações que são traçadas entre a política e o direito, visto que estas revelam forte influência no processo interativo dos atores políticos envolvidos na construção das decisões institucionais. Não obstante a tendência brasileira dos últimos anos em consolidar a prática da jurisdição constitucional e a prestigiar institucionalmente o STF, por meio das teorias dialógicas, busca-se conciliar o princípio da supremacia judicial com uma leitura que reconheça o papel do Legislativo, em especial, e do Executivo na ordem política e social. Entende-se que, assim, haveria uma maior garantia de direitos, a construção de um processo deliberativo quanto ao conteúdo dos direitos nas questões difíceis e a prevenção à prática judicial ativista. (SILVA; BERMAN; TAVARES; VALLE, 2010)

Nessa perspectiva, defende-se que a legitimidade e a eficácia de um sistema de cotas nacional ficam condicionadas à possibilidade de se estabelecer uma relação de deliberação de cunho dialógico entre os poderes do Estado ${ }^{18}$, as universidades e a sociedade. Pontua-se que tal interação seria essencial para que as diretrizes sobre essas ações afirmativas pudessem partir de um conjunto de princípios unificado, capaz de evitar divergências que rompessem com a legitimidade e a segurança jurídica. Assim, haveria a completude necessária para a harmonização dos entendimentos, em nível nacional, recusando-se, portanto, uma visão unicamente pautada no monopólio judicial da interpretação da Constituição e (ou) na exclusiva deliberação das universidades.

Todavia, como será demonstrado, no cenário brasileiro, ocorre ainda a falta de um real debate sobre o tema, o qual promova efetivamente uma maior elucidação em

${ }^{17}$ Princípio da hermenêutica constitucional contemporânea que representa a ideia de que nenhuma norma constitucional pode ser suprimida por estar no ponto mais alto hierarquicamente do ordenamento jurídico (atendendo-se à perspectiva kelseniana de ordenamento jurídico escalonado). Somente uma norma constitucional poderia justificar a inaplicação de outra. Esse princípio é visto como um pressuposto para a compreensão de outros, como a Proporcionalidade e a Harmonização (ou Conformidade Prática) - ao lado do princípio da Unidade das Normas Constitucionais -, uma vez que os princípios constitucionais só precisam se compatibilizar entre si por não poder negar a normatividade um do outro. Também é um pressuposto para entender a noção de Controle de Constitucionalidade - ao lado da Rigidez Constitucional -, justificando o fato de se verificar a compatibilidade entre uma norma examinada, infraconstitucional, com as determinações de outra norma paradigma que lhe seja superior normativamente.

${ }^{18}$ Hübner Mendes (tese, 2008, p. 98) ensina que haveria dois denominadores comuns nas teorias do diálogo: “a recusa da visão juricêntrica e do monopólio judicial na interpretação da constituição, a qual é e deve ser legitimamente exercida pelos outros poderes; a rejeição da existência de uma última palavra, ou, pelo menos, de que a corte a detenha por meio da revisão judicial". 
relação aos anseios e valores da sociedade, de forma a incrementar as condições materiais de igualdade e evitar possíveis parcialidades. Nesse sentido, o que pode ser definido como a problematização, no que tange ao sistema de cotas universitárias brasileiro, seria a falta de uniformidade e coesão nos critérios estabelecidos nos editais e a ausência de um efetivo diálogo entre as instituições.

\subsection{A IMPLANTAÇÃO DO SISTEMA DE COTAS PELAS INSTITUIÇÕES DE ENSINO SUPERIOR PÚBLICAS}

Os editais universitários e as legislações que instituem cotas para o acesso às universidades públicas permitem verificar quais são os conceitos e critérios mais utilizados no que tange à efetivação institucional desta espécie de ação afirmativa. Assim, a partir da análise de cinquenta e seis desses editais de ingresso, desde o ano de 2009 até 2012 , percebeu-se que há uma considerável diversidade nos sistemas implantados, tanto na definição dos grupos beneficiados quanto na quantidade de vagas reservadas.

Em relação à natureza das cotas, verificou-se que, em regra, há três grandes categorias adotadas, podendo seus critérios ser aplicados cumulativamente ou não: a) cota racial - os beneficiados são os cidadãos que pertencem a uma determinada raça ou origem étnica; b) cota para egresso de escola pública - para aqueles que cursaram o ensino fundamental e (ou) médio em escolas públicas; c) cota social - os contemplados por esta reserva devem comprovar um valor de renda familiar baixo, o qual será fixado previamente por cada instituição. A categoria de cota beneficiada, de forma mais frequente, foi aquela composta por alunos egressos de escolas públicas e carentes. Observou-se, entretanto, uma dificuldade no entendimento do próprio termo egresso de escola pública, pois, dependendo do edital, haveria a imposição de requisitos bastante distintos.

Curiosamente, em alguns casos, havia a estipulação de cotas para grupos menos prováveis, como, por exemplo, no caso da UERJ, em que há cota para filhos de policiais e bombeiros militares, inspetores de segurança e agentes penitenciários mortos ou feridos em serviço ou na UFAL ${ }^{19}$, em que havia $20 \%$ de cota para candidatos negros oriundos de escolas públicas, sendo que desse percentual, 60\% era reservado para mulheres. Um ponto polêmico que se levanta é quando a reserva de vagas tem como objetivo superar as adversidades de ordem regional, estabelecendo que apenas poderá ser beneficiado pela cota quem residir em determinado local dentro do estado. ${ }^{20}$

${ }^{19}$ Edital de ingresso na Universidade Federal de Alagoas referente ao ano de 2011.

${ }^{20}$ Neste sentido, podemos citar como exemplos: a) a Universidade Federal Rural de Pernambuco, em que o candidato que havia cursado o ensino médio integralmente em escola pública de qualquer uma das microrregiões de Pernambuco pertencente ao Agreste ou ao Sertão teria um acréscimo de 10\% em sua nota final, caso optasse pelos cursos de Garanhuns e Serra Talhada (edital de ingresso referente o ano de 2011); b) o Centro Universitário Municipal de São José (SC) que reserva 70\% de suas vagas para alunos das escolas públicas (municipal, estadual, federal) de São José. 
No que tange à eficácia, embora não seja comum, o sistema de cotas instituído pode prever normas que deem conta do controle de seus beneficiados ao longo do curso ou após a sua diplomação, conforme consta no art. $1^{\circ}$, parágrafos $6^{\circ}$ e $7^{\circ}$, da Lei n. ${ }^{\circ}$ 5.346, responsável por estabelecer o sistema de cotas na UERJ ${ }^{21}$.

Do mapeamento que vem sendo realizado anualmente, em mais de 50 universidades, acerca do tratamento oferecido aos sistemas de cotas universitárias, percebeu-se uma possível falta de uniformidade quanto aos critérios e conceitos estabelecidos nos editais e uma inicial ausência de publicização dos fundamentos responsáveis por estruturar esta medida.

\subsection{O POSICIONAMENTO DO JUDICIÁRIO NACIONAL}

No Poder Judiciário nacional, a maioria dos magistrados mostra-se completamente favorável a esta ação afirmativa, demonstrando certa preferência em relação às cotas sociais. Nos dados levantados, percebe-se que a polêmica repercutiu na grande maioria dos tribunais brasileiros, tanto em âmbito federal quanto estadual, chegando às instâncias superiores. Observou-se que, nas decisões, a norma jurídica é "construída" por meio de princípios constitucionais, em especial, da legalidade, proporcionalidade, autonomia universitária e igualdade (material). Raramente, o magistrado lança mão de recursos argumentativos interdisciplinares, deixando a cargo da instituição de ensino os fundamentos sociais, históricos e culturais que possam embasar os critérios estabelecidos.

No Estado do Rio de Janeiro, levantou-se que há um elevado número de decisões no Tribunal de Justiça acerca do sistema de cotas adotado pelas universidades de sua competência. Inicialmente, em alguns casos, prevaleceu o argumento em prol da defesa da inconstitucionalidade das distintas legislações que instituíram cotas em universidades públicas do estado, aplicando-se argumentos como a violação dos princípios da proporcionalidade, da razoabilidade e da isonomia ${ }^{22}$. Em contrapartida, posteriormente, destacou-se no Tribunal a proteção da igualdade de oportunidades esboçada na Constituição Federal, na medida em que se entendeu que as cotas promoveriam a ampliação do acesso à universidade para negros, pardos e egressos da rede pública de

${ }^{21}$ Art. $1^{\circ} \$ 6^{\mathbf{0}}$ No prazo de um ano anterior ao fim do prazo de prorrogação estabelecido no caput deste artigo, o Poder Executivo instituirá comissão para avaliar os resultados do programa de ação afirmativa, presidida pelo Procurador-Geral do Estado, com representantes dos órgãos e entidades participantes do referido programa, além de representantes das instituições da sociedade civil, em cada etnia ou segmento social objeto desta Lei. § $7^{\mathbf{0}} \mathrm{O}$ Relatório da avaliação do programa será publicado e encaminhado à Assembléia Legislativa do Estado do Rio de Janeiro - ALERJ, para fins de acompanhamento.

${ }^{22}$ Brasil. Rio de Janeiro. Tribunal de Justiça. Arguição de Inconstitucionalidade n. ${ }^{0}$ 2005.017.00015; Apelação Cível n. ${ }^{\circ}$ 2004.001.06281; Apelação Cível n. ${ }^{\circ} 2004.001 .10830$; Apelação Cível n. ${ }^{\circ}$ 2003.001.35251. 
ensino. Portanto, o argumento da proteção da igualdade substancial ou material prevaleceu sobre os critérios de isonomia formal ${ }^{23}$.

Restou assente que o princípio da isonomia deve garantir que as normas não sejam, simplesmente, elaboradas e aplicadas a todos os indivíduos, mas deve-se observar que existem grupos hipossuficientes que necessitam de uma proteção especial para que alcancem a igualdade real, esta sim decorrente do princípio da dignidade da pessoa humana ${ }^{24}$. Verificou-se ainda a preocupação deste Tribunal na proteção dos chamados não cidadãos, que seriam aqueles excluídos da participação política na vida do Estado, em virtude de fatores reais de ordem socioeconômica ${ }^{25}$. Pode-se considerar que os conceitos e fundamentos foram discutidos sob uma óptica quase que estritamente jurídica, havendo também um posicionamento de caráter político-ideológico dos magistrados.

Nas decisões observadas no Tribunal Regional Federal da $2^{\circ}$ Região, observouse a prevalência pelo posicionamento em favor da constitucionalidade no sistema de cotas universitárias ${ }^{26}$. $\mathrm{O}$ argumento recorrentemente foi o princípio da autonomia universitária previsto na Constituição Federal em seu artigo 207, de forma que o poder Judiciário não teria o condão de opinar sobre os critérios adotados por cada universidade para estabelecer a quantidade de vagas reservadas, tendo em vista o princípio da separação dos poderes. Reforçaram também que o sistema de cotas protege o princípio da isonomia ao mitigar as desigualdades sociais, sem suprimir a exigência do mérito na concorrência, mas tão somente atribuindo novas formas de valoração de grupos sociais desfavorecidos que necessitam de amparo especial.

Já no TRF da $4^{\circ}$ Região, encontramos um posicionamento mais distinto entre as turmas, mesmo que a apoio às ações afirmativas venha se mostrando crescente.

Parte da jurisprudência defende a inconstitucionalidade das cotas universitárias e argumenta que os editais das universidades púbicas não são instrumentos adequados para a instituição desse tipo de política de ação afirmativa, tendo em vista que restringe direitos fundamentais garantidos na Constituição. Com efeito, qualquer restrição ao princípio da igualdade, portanto com o poder de inovar, deveria ser estabelecida por meio de legislação aprovada pelo Congresso $\mathrm{Nacional}^{27}$.

${ }^{23}$ Brasil. Rio de Janeiro. Tribunal de Justiça. Apelação Cível n. ${ }^{\circ}$ 2004.001.12910; Agravo de Instrumento n. ${ }^{\circ} 2003.002 .05345$.

${ }^{24}$ Brasil. Rio de Janeiro. Tribunal de Justiça. Ação Direta de Inconstitucionalidade n. ${ }^{\circ}$ 2009.007.00009.

${ }^{25}$ Brasil. Rio de Janeiro. Tribunal de Justiça. Apelação Cível n. ${ }^{\circ}$ 2005.001.27062.

${ }^{26}$ Brasil. Tribunal Regional Federal da $2^{\circ}$ Região. Apelação Cível n. ${ }^{\circ} 470453$; Apelação Cível n. ${ }^{\circ} 465416$; Apelação Cível n. ${ }^{\circ} 470393$; Apelação Cível n. ${ }^{\circ} 430777$; Agravo de Instrumento n. ${ }^{\circ} 174387$.

${ }^{27}$ Brasil. Tribunal Regional Federal da $4^{\circ}$ Região. Órgão julgador: Quarta Turma. Processo: 0002699 34.2009.404.7102. Relatora: Marga Inge Barth Tessler. 
Por outro lado, as decisões em apoio ao sistema de cotas fazem uso de uma interpretação teleológica da Constituição, capaz de buscar os seus reais objetivos na promoção da igualdade social. ${ }^{28}$ As referidas decisões mostram forte influência da doutrina e da jurisprudência norte-americanas, de onde se retirou o argumento de que as políticas que instituem ações afirmativas devem estar profundamente motivadas e ser passíveis de uma análise pormenorizada por parte do Judiciário, do Legislativo e da Administração. As políticas públicas que restringem direitos fundamentais devem ser amplamente motivadas e estar em conformidade com a promoção de outros bens comuns de caráter constitucional. Alguns julgados ressaltaram também que o sistema de cotas deve atender a determinados requisitos constitucionalmente estabelecidos, embasados no princípio da proporcionalidade ${ }^{29}$.

Atualmente, tramitam no Supremo Tribunal Federal alguns processos que envolvem a problemática da implantação de ações afirmativas nas universidades públicas. De forma a enriquecer o debate sobre o tema, em março de 2010, houve a realização de uma Audiência Pública que contou com a ampla participação de vários setores da sociedade. O processo de maior relevância foi a Arguição de Descumprimento de Preceito Fundamental n. ${ }^{\circ} 186^{30}$, a qual foi ajuizada pelo Partido Democratas, sob a alegação de que a política de cotas adotada na UnB feriria vários preceitos fundamentais da Constituição Federal.

Em sede de liminar, o Ministro Gilmar Mendes proferiu entendimento favorável ao sistema de ações afirmativas, desde que ele esteja circunscrito pelas características socioculturais da população e que seja temporário. Ressaltou que, na qualidade de medidas de emergência, ante a urgência de se encontrar uma solução para os problemas de discriminação racial, as ações afirmativas não constituem subterfúgio e, portanto, não excluem a adoção de medidas de longo prazo, como, por exemplo, a melhora das condições do ensino fundamental.

Observou ainda a dificuldade de acesso ao ensino superior no país para determinadas parcelas da população e que devem ser fomentadas políticas públicas prioritárias e inclusivas voltadas às etapas anteriores (educação básica) e alternativas (cursos técnicos). Em relação à problemática que envolve o conceito de "raça", afirmou que este não comporta fundamentação biológica, tendo com base o precedente criado

${ }^{28}$ Brasil. Tribunal Regional Federal da $4^{\circ}$ Região. Órgão julgador: Terceira Turma. Processo: 2009.72.00.0010787. Relator: João Pedro Gebran Neto; Processo: 2009.04.00.004965-0. Relator: Luiz Carlos de Castro Lugon.

${ }^{29}$ Brasil. Tribunal Regional Federal da $4^{\circ}$ Região. Apelação/Reexame Necessário n. ${ }^{\circ}$ 2009.72.00.001078-7; Apelação/Reexame Necessário n. ${ }^{\circ}$ 2009.72.00.004201-6; Apelação Cível n. ${ }^{\circ}$ 2008.71.00.004104-2.

${ }^{30}$ Brasil. Supremo Tribunal Federal. ADPF n. ${ }^{\circ} 186$. Relator: min. Ricardo Lewandowski. 
no julgamento do caso Ellwanger ${ }^{31}$. Por fim, no julgamento do pedido de medida cautelar, o Ministro Gilmar Mendes entendeu que, naquele momento, não se vislumbrava qualquer razão para a suspensão do registro dos alunos que foram aprovados no último vestibular da UnB ou para qualquer interferência no andamento dos trabalhos na universidade.

Em abril de 2012, houve o julgamento de mérito pelo plenário desta Arguição de Descumprimento de Preceito Fundamental. Os ministros seguiram o voto do relator do caso, o ministro Ricardo Lewandowski, que julgou pela improcedência da ADPF. Vale ressaltar que o jurista entendeu que era conveniente que o STF, naquele momento, resolvesse definitivamente a controvérsia que já se arrastava, sem solução definitiva, por várias décadas nas distintas instâncias jurisdicionais do país. Percebe-se que o ministro expressamente posicionou-se a favor de uma supremacia judicial, ainda mais quando as demais instituições permanecerem inertes na sociedade.

Foi pontuada a importância das políticas de ação afirmativa, seu histórico e transitoriedade, considerando que estas teriam como objetivo estabelecer um ambiente acadêmico plural e diversificado, superando distorções sociais historicamente consolidadas. Quanto ao critério de ingresso nas universidades, entendeu-se que este deve se dar para além da meritocracia, contemplando as diversas aptidões dos candidatos, conjugando o conhecimento técnico e a criatividade intelectual ou artística com a capacidade potencial que ostentam para intervir nos problemas sociais. Além disso, observou-se que deve-se levar em consideração critérios étnico-raciais ou socioeconômicos, de modo a assegurar que a comunidade acadêmica e a própria sociedade sejam beneficiadas pelo pluralismo de ideias.

Colocou-se que o princípio da igualdade, principalmente em seu viés material, representaria uma justificativa para que o Estado pudesse utilizar-se de ações afirmativas que atingem grupos sociais determinados, de maneira pontual, atribuindo a estes certas vantagens, por um tempo limitado, de modo a permitir-lhes a superação de desigualdades decorrentes de situações históricas particulares. Para o ministro, as referidas cotas universitárias não violariam os princípios da proporcionalidade e da razoabilidade, uma vez que: I) os métodos seletivos que vêm sendo realizados, tomando como base as cotas, mostraram-se eficazes e compatíveis com o princípio da dignidade humana; II) encontra-se prevista a revisão periódica de seus resultados; III) são ações afirmativas transitórias.

Dentre os argumentos proferidos, o ministro utilizou-se de um bastante interessante para respaldar as políticas de ação afirmativa, aduziu que ela seria responsável pela criação de lideranças entre os grupos discriminados capazes de lutar pela defesa de seus direitos, além de servirem como paradigmas de integração e ascensão social. Haveria, portanto, um importante componente psicológico multiplicador da inclusão social nessas

${ }^{31}$ Brasil. Supremo Tribunal Federal. HC 82.424-2/RS. 
políticas. Por outro lado, salientou que a histórica discriminação dos negros e pardos revelaria igualmente um componente multiplicador, mas às avessas, uma vez que perpetuaria uma consciência de inferioridade e de conformismo com a falta de perspectiva. Seguindo esse raciocínio, o ministro defendeu as polêmicas cotas raciais, ponderando que a utilização exclusiva do critério social ou de baixa renda para promover a integração social de grupos excluídos mediante ações afirmativas seria insuficiente, devendo-se incorporar considerações de ordem étnica e racial.

Quanto ao conceito de raça, Lewandowski seguiu a jurisprudência do Supremo, ao entender que se trata de "um conceito histórico-cultural, artificialmente construído, para justificar a discriminação ou, até mesmo, a dominação exercida por alguns indivíduos sobre certos grupos sociais, maliciosamente reputados inferiores." ${ }_{32}$ Nesse sentido, ponderou que, não obstante os programas de ação afirmativa tomarem como ponto de partida a consciência de raça existente nas sociedades, eles têm como escopo final eliminá-la.

Percebe-se que a recente decisão de mérito manteve um alto nível de profundidade, bem como anunciou a decisão liminar. Realizou-se uma marcante revisão bibliográfica com autores nacionais e internacionais de grande relevância, além de uma análise de conceitos e critérios relativos às cotas universitárias e à ponderação de princípios

constitucionais. É possível afirmar que a amplitude do não provimento será vasta, uma vez que, julgada a ação, a decisão é imediatamente autoaplicável, tendo eficácia erga omnes e efeito vinculante, relativamente aos demais órgãos do Poder Público, além de efeitos retroativos (LENZA, 2010, p. 303).

\subsection{A AUSÊNCIA DE UMA NORMA GERAL}

Conforme se verifica, não há uma norma geral que respalde e estabeleça parâmetros nacionais para os sistemas de cotas, haja vista a ausência do trato do tema em lei específica ou mesmo nas Diretrizes e Bases da Educação e no Estatuto da Igualdade. Percebe-se que, quando as cotas são reguladas por lei, esta parte de iniciativa estadual, da Assembleia Legislativa, não obstante algumas divergências quanto à competência do órgão e a constitucionalidade de tal lei.

Atualmente, consta no Senado o projeto de lei da Câmara n. ${ }^{o} 180$ de $2008^{33}$. Este tem como origem o PL 73/99 da Câmara dos Deputados de autoria da deputada Nice Lobão. O projeto sofreu algumas alterações e incorporou outros de mesmo teor (PLS 344/2008 e o PLS 479/2008), visto que o objetivo central era uniformizar os processos seletivos, por meio de cotas nas universidades e instituições federais públicas de ensino

${ }^{32}$ Brasil. Supremo Tribunal Federal. ADPF n. ${ }^{\circ} 186$. Voto do min. Relator Ricardo Lewandowski. fl. 20.

${ }^{33}$ A íntegra do projeto encontra-se no site do Senado. Fonte: < http://www.senado.gov.br/atividade/materia/ getPDF.asp? $\mathrm{t}=53196 \& \mathrm{tp}=1>$. 
superior. Da leitura desses textos normativos, entende-se que o Poder Legislativo coloca como relevantes critérios sensíveis à raça e à condição econômica.

Em sua tramitação, observa-se que esta tornou-se mais célere a partir do fim de 2011, quando na Comissão de Constituição, Justiça e Cidadania a Senadora Ana Rita apresentou, em seu relatório, voto favorável ao Projeto. No documento, foi afirmado que o presente tema era matéria de competência comum e concorrente da União e que as ações afirmativas seriam constitucionais, uma vez que representariam medidas para combater a desigualdade social. ${ }^{34}$ Em junho de 2012, esse parecer foi aprovado pela referida comissão, sendo o projeto remetido para a Comissão de Direitos Humanos e Legislação Participativa. Ainda neste mês, o PLC n. ${ }^{\circ} 180$ foi devolvido pelo Senador Paulo Paim com relatório, concluindo pela sua aprovação. No momento, encontra-se na área de coordenação legislativa do Senado. ${ }^{35}$

De acordo com o projeto, as instituições federais de educação superior vinculadas ao MEC devem reservar, em cada concurso seletivo para ingresso nos cursos de graduação, por curso e por turno, no mínimo 50\% de suas vagas para estudantes que tenham cursado integralmente o ensino médio em escolas públicas. No preenchimento dessas vagas, a metade deverá ser reservada aos estudantes com famílias com renda igual ou inferior a 1,5 salário mínimo per capita, e os outros $25 \%$ deverão ser reservados para os estudantes que se autodeclararem negros, pardos ou indígenas, conforme dados do Censo do IBGE da região. Está previsto que as instituições federais de educação superior terão o prazo máximo de quatro anos para o cumprimento integral do disposto nesta Lei, sendo que deverão implementar ao menos $25 \%$ da reserva de vagas a cada ano.

Em dezembro de 2011, o Senador Demóstenes Torres requereu a realização de uma nova audiência pública, mas esta foi rejeitada, visto que a CCJ já havia promovido três debates entre dezembro de 2008 e abril de 2009. Vale ressaltar que há outros projetos de lei que versam sobre o sistema de cotas e a reforma universitária, contudo, a movimentação destes não é recente. $\mathrm{O}$ que se pode analisar do referido projeto é que, caso se torne lei, haverá uma maior definição sobre a forma que as universidades devem promover o seu sistema de cotas, visto a prévia deliberação em relação à espécie que deverá ser adotada e o quantum aplicado.

\subsection{A ATUAÇÃO DO EXECUTIVO NACIONAL}

No Brasil, apenas na década de 1990, durante o governo do então presidente Fernando Henrique Cardoso, o tema das ações afirmativas entrou na agenda do governo,

${ }^{34}$ Fonte: <http://www6.senado.gov.br/mate-pdf/100663.pdf $>$.

${ }^{35}$ Consulta realizada no dia 12 de julho de 2012. Fonte: < http://www.senado.gov.br/atividade/materia/ detalhes.asp?p_cod_mate $=88409>$. 
com a criação do Grupo de Trabalho Interministerial para a Valorização da População Negra (1995), as propostas do Programa Nacional de Direitos Humanos (1996) e a participação do Brasil na Conferência Mundial contra o Racismo, Discriminação Racial, Xenofobia e Formas Correlatas de Intolerância (2001), na África do Sul.

A partir do ano de 2000, o então presidente Luiz Inácio Lula da Silva aprofundou e concretizou o processo de inclusão de ações afirmativas na sociedade. Criou-se a Secretaria Especial para a Promoção da Igualdade Racial e o Programa Universidade para Todos, prevendo bolsas e vagas específicas para determinados grupos. Houve ainda uma modificação no Sistema de Financiamento ao Estudante. Em 2003, o Conselho Nacional de Educação exarou as Diretrizes Nacionais Curriculares para a Educação das Relações Étnico-Raciais e para o Ensino da História e Cultura Afro-Brasileira.

Entre os anos de 2004 e 2005, o MEC trabalhou no sentido de uma reforma universitária baseada na constatação de que o Sistema de Educação Superior Federal necessitava de uma regulação orgânica fundada em princípios contemporâneos. Esta tinha como uma de suas diretrizes aprofundar a política de cotas nas universidades, priorizando os alunos provenientes do Sistema Público e a criação de cotas étnicas. A implantação seria gradual nos cursos, totalizando aproximadamente 50\% das vagas. Pontuou-se também que, com a recuperação gradativa da qualidade do ensino médio público, haveria a possibilidade de uma política regressiva de cotas, considerando que os alunos oriundos de escolas públicas já estariam aptos a concorrer às vagas independentemente da reserva. ${ }^{36}$

As normas propostas pelo MEC não chegaram a virar lei, mais impactaram positivamente as instituições de ensino, de forma que estas vêm adotando medidas de inclusão na universidade, reconhecendo a pluralidade e a diversidade regional, como o sistema de cotas em seu vestibular, mesmo sem ter como base uma norma geral ou a edição de uma diretriz única do governo. Além disso, vale ressaltar que, nos últimos anos, houve a criação e a expansão das universidades públicas e dos cursos técnicos.

\section{O CASO UERJ - UM EXEMPLO POSITIVO DE DIÁlOGO INSTITUCIONAL}

Em 2003, a Universidade do Estado do Rio de Janeiro foi pioneira em estabelecer a reserva de $50 \%$ de suas vagas para estudantes que se encontravam em condições raciais e (ou) sociais desfavoráveis e, desde então, manteve as cotas em seu vestibular, alterando critérios e porcentagens, quando necessário. Escolheu-se, assim, realizar um estudo mais aprofundado sobre o comportamento da instituição e dos demais poderes, em âmbito estadual, em razão do tempo de implantação do sistema de cotas, dos

\footnotetext{
${ }^{36}$ Fonte: < http://www.fedepsp.org.br/superior/MEC\%2002-08-04.htm > .
} 
mecanismos criados pela universidade para recepcionar os alunos cotistas e diminuir as tensões e a polêmica gerada na sociedade carioca no trato deste tema.

Como fundamento para a aplicação prática do sistema de cotas, a instituição alega acreditar que esta Política de ações afirmativas atua como um importante vetor de inclusão social pela inclusão acadêmica. Afirma também que esta seria parte da solução do problema relativo à dificuldade de acesso à universidade, mesmo que seja uma medida temporária, e sempre deve vir acompanhada de uma política de permanência (RIBEIRO SOUZA, 2010).

Além disso, ressalta-se que a universidade realizou uma série de estudos sobre o tema e dispõe de uma ampla base de dados. Podemos citar como exemplos o Laboratório de Políticas Públicas que, em 2001, criou o Programa Políticas da Cor na Educação Brasileira $^{37}$ e a minuciosa análise estatística realizada quanto às características dos estudantes escritos e classificados, desde $2004^{38}$.

Desde a implantação das cotas nesta universidade, ela vem sendo regulada primordialmente por lei estadual. Atualmente, encontra-se em vigor a Lei n. ${ }^{\circ} 5346 / 08^{39}$ e, complementando-a, há a lei federal n. ${ }^{0} 7.853 / 89^{40}$ e os Decretos n. ${ }^{\circ} 3.298 / 99^{41}$ e n. ${ }^{\circ}$ $5.296 / 04^{42}$, os quais dizem respeito ao portador de necessidades especiais. Esta lei foi elaborada em uma dinâmica entre a própria universidade, a ALERJ e o governo do estado, o que indica uma articulação no sentido da configuração de um diálogo institucional.

Contudo, a referida lei estadual foi objeto da Representação de Inconstitucionalidade n. ${ }^{\circ}$ 9/2009, com o pedido formulado pelo Deputado Estadual Flavio Nantes Bolsonaro ${ }^{43}$.

${ }^{37}$ Fonte: < http://www.lppbuenosaires.net/olped/acoesafirmativas/PPCORFASEII/faseII_apresentacao.asp >

${ }^{38}$ Fonte: <http://www.vestibular.uerj.br/portal_vestibular_uerj/2010/dados_estatisticos/dados_estatisticos.php > .

${ }^{39}$ Dispõe sobre o novo sistema de cotas para ingresso nas universidades estaduais e dá outras providências.

${ }^{40}$ Dispõe sobre o apoio às pessoas portadoras de deficiência, sua integração social, sobre a Coordenadoria Nacional para Integração da Pessoa Portadora de Deficiência-Corde, institui a tutela jurisdicional de interesses coletivos ou difusos dessas pessoas, disciplina a atuação do Ministério Público, define crimes, e dá outras providências.

${ }^{41}$ Regulamenta a Lei n. ${ }^{0}$ 7.853, de 24 de outubro de 1989, dispõe sobre a Política Nacional para a Integração da Pessoa Portadora de Deficiência, consolida as normas de proteção, e dá outras providências.

${ }^{42}$ Regulamenta as Leis 10.048 , de 8 de novembro de 2000, que dá prioridade de atendimento às pessoas que especifica, e 10.098, de 19 de dezembro de 2000, que estabelece normas gerais e critérios básicos para a promoção da acessibilidade das pessoas portadoras de deficiência ou com mobilidade reduzida, e dá outras providências.

${ }^{43}$ Ementa: "Discriminação Positiva. Ações Afirmativas. Igualdade Formal e Material. Constitucionalidade. "Os direitos são os mesmos para todos, mas como nem todos se acham em igualdade de condições para os exercer, é preciso que estas condições sejam criadas ou recriadas através da transformação da vida e das estruturas dentro das quais as pessoas se movem (...) mesmo quando a igualdade social se traduz na concessão de certos direitos ou até certas vantagens especificamente a determinadas pessoas - as que se encontram em situações de inferioridade, de carência, de menor proteção - a diferenciação ou a discriminação positiva tem em vista alcançar a igualdade e tais direitos ou vantagens configuram-se como instrumentais no rumo para esses fins" (Jorge Miranda, Manual de 
No caso, a UERJ entrou como amicus curiae para defender o seu sistema de cotas. Em 2009, o Des. Murta Ribeiro decidiu suspender a eficácia da lei, em pedido liminar, com voto que aparentava, em certas passagens, um caráter técnico-neutro ${ }^{44}$. Porém, é possível identificar passagens que demonstram como a denegação da liminar teve caráter políticoideológico, pois o Desembargador deixou claro o seu posicionamento contrário a medidas desta natureza ${ }^{45}$.

No julgamento de mérito, o relator Des. Sérgio Cavalieri Filho julgou improcedente a representação, uma vez que entendeu pela constitucionalidade da lei que regula o sistema de cotas na universidade, afirmando que a lei de cotas seria, em verdade, um diploma concretizador de direitos de constitucionalidade induvidosa. Em seu voto, o desembargador sustentou, em algumas passagens, alguma neutralidade e certa preocupação com o princípio da separação dos poderes, "[s]e a referida lei é boa ou má, se vai produzir efeitos positivos ou negativos, se o legislador adotou ou não o melhor critério, não são questões afetas ao Judiciário." Todavia, ao decorrer, o posicionou-se claramente favorável ao sistema de cotas:

É preciso que se entenda que a política de cotas, embora de cunho emergencial e temporário, não é algo paternalista. Ela promove uma transformação social que acelera as outras mudanças que com ela são necessárias para o progresso do Estado. (...) Nesses anos todos em que a lei de cotas tem vigido em nosso Estado, revelou-se um sucesso.

No caso, o sistema de cotas foi abordado de forma profunda, sob a óptica jurídica, em especial constitucional. Buscou-se contextualizar criticamente o tema à realidade social

Direito Constitucional, $3^{\text {a }}$ ed, tomo IV, Coimbra Editora, p. 225). A igualdade somente pode ser verificada entre pessoas que se encontram em situação equivalente, sendo levados em consideração os fatores ditados pela realidade econômica, social e cultural. O princípio da isonomia garante que as normas não devem ser simplesmente elaboradas e aplicadas a todos os indivíduos; vai além na medida em que considera a existência de grupos minoritários e hipossuficientes, que necessitam de uma proteção especial para que alcancem a igualdade real, esta sim uma exigência do princípio maior da dignidade da pessoa humana. Portanto, a igualdade prevista na Constituição Federal e repetida na Constituição do Estado do Rio de Janeiro é a igualdade substancial. Se assim não fosse, ainda estaríamos na época do Império, cuja Carta consagrava o princípio da igualdade, mas permitia a convivência do indigitado princípio com a vergonha do regime escravocrata. A ação afirmativa liga-se por um vínculo inquebrantável ao princípio da isonomia. Ela é o instrumento eficaz a garantir sua concretização no seio da sociedade que, a exemplo da nossa, já nascem marcadas pela desigualdade e pelo preconceito. Neste contexto, a Lei de Cotas (Lei Estadual n. ${ }^{\circ}$ 5.346/08) surge não como um diploma concessivo de direitos, vez que estes já são assegurados na Constituição e em outros diplomas. A Lei de Cotas, em verdade, é diploma concretizador de direitos, de constitucionalidade induvidosa. Improcedência da representação" (grifos do original). (Brasil. Rio de Janeiro. Tribunal de Justiça. Órgão Especial. Representação de inconstitucionalidade n. ${ }^{\circ}$ 2009.007-00009)

44 “(...) entendo de suspender a eficácia desta nova lei instituidora de cotas nas Universidades Estaduais em pedido liminar, até que se julgue em definitivo o meritum causae, quando então se poderá fazer mais aprofundado exame doutrinário filosófico de tão relevante questão social. Por ora, se fica na posição técnico - jurídica intransponível". Representação de inconstitucionalidade - 2009.007-00009.

45 "Concessa máxima vênia das doutas posições divergentes, não devemos criar um estímulo à divisão racial no Brasil". Representação de inconstitucionalidade - 2009.007-00009. 
brasileira. Entretanto, não houve um trabalho interdisciplinar sobre as cotas universitárias, fato este recorrente nas decisões judiciais sobre o tema. $\mathrm{O}$ desembargador Sérgio Cavalieri desenvolveu, em seu voto, conceitos como o de igualdade formal e igualdade material, descriminação positiva, ação afirmativa, racismo, desigualdade e violência.

Após três embargos de declaração, o acórdão foi publicado somente em 2011. A questão do caso UERJ encontra-se agora aguardando seu primeiro juízo de admissibilidade para Recurso Extraordinário na $3^{\text {a }}$ vice-presidência. É possível afirmar que houve, no caso UERJ, um diálogo entre a universidade, a ALERJ - como representante do Poder Legislativo, o TJERJ - como representante do Poder Judiciário e o Governo do Estado. Dificilmente os sistemas de cotas, no Brasil, enquadram-se neste perfil, mas é possível identificar este exemplo positivo de diálogo institucional, em que o princípio da igualdade material foi sempre utilizado como argumento na deliberação das instituições envolvidas.

\section{CONSIDERAÇÕES FINAIS}

Nos últimos anos, o direito social à educação tornou-se uma preocupação latente, em razão do ainda baixo percentual de estudantes que consegue se formar no ensino superior e público. Diante desse cenário, as universidades públicas brasileiras resolveram concretizar instrumentos que possam proporcionar uma maior inclusão e diversidade na instituição. Assim, houve a implantação do sistema de cotas, uma vez que se entendeu que este seria capaz de influenciar o rumo cultural e social da nação, além de estimular os valores de fraternidade e igualdade.

Todavia, essa atitude gerou uma grande polêmica na sociedade, repercutindo diretamente nos poderes do Estado e nas universidades, tendo em vista os pedidos de declaração de inconstitucionalidade de leis que regulamentam ações afirmativas, as decisões confrontantes e a manifestação, de ambos os lados, de vários grupos na sociedade. Nesse sentido, buscou-se no presente estudo realizar uma análise do comportamento institucional, seu desenvolvimento e possíveis vulnerabilidades que poderiam prejudicar a promoção do princípio da igualdade material por meio das cotas universitárias.

Em relação aos editais universitários, constatou-se que há uma pluralidade considerável de critérios relativos à aplicação das cotas, havendo ainda à falta de uma uniformização entre as instituições de ensino. Em certos casos, verificou-se também a ausência de uma maior publicização dos fundamentos constitucionais-democráticos que foram utilizados para embasar, objetivamente, os critérios adotados quanto às categorias e aos percentuais de reserva. Percebeu-se que o tipo de cota mais comum entre as universidades contempla aqueles que têm uma condição social menos favorecida. 
No Poder Judiciário, apesar de algumas divergências quanto à constitucionalidade desta espécie de ação afirmativa, majoritariamente, houve um entendimento favorável a sua implantação, em especial quando as cotas beneficiam grupos que se encontram excluídos por questões socioeconômicas. Na recente decisão de mérito do STF sobre o tema, quando julgou-se que as cotas da UnB não feririam qualquer preceito fundamental da Constituição Federal, percebeu-se que o relator de forma expressa desejou por um fim ao debate, atribuindo implicitamente à decisão do órgão uma supremacia em relação ao posicionamento das demais instituições.

No Poder Legislativo federal, ao longo de mais de 10 anos, ocorreram diversas mudanças no texto do projeto de lei que seria responsável por orientar as reservas de vagas nas universidades públicas. No momento, o projeto encontra-se no Senado com a referência PLC n. ${ }^{\circ} 180$ de 2008. Ressalta-se a importância desta regra, visto que, embora haja um exemplo positivo no caso da UERJ, em que a legislação estadual criou as diretrizes básicas do sistema de cotas da universidade, o Brasil carece de uma legislação federal que trace metas e diretrizes para as cotas nas universidades públicas, visando orientar, a partir de um plano unificado, os critérios dos editais e a própria jurisprudência dos tribunais.

Todavia, após a decisão do STF na ADPF 186, parece que a presente ausência normativa tende a mudar, já que, no ano de 2012, a tramitação no Senado do referido projeto de lei vem se tornando mais célere. Nos relatórios e pareceres, os senadores vêm adotando uma postura favorável às cotas universitárias, utilizando-se de argumentos que há anos a doutrina especializada trabalha. Além disso, esta posição do legislativo encontrase em total consonância com o entendimento do Judiciário nacional e com os programas do Executivo.

O Poder Executivo, por sua vez, vem trabalhando no sentido de implantar uma série de medidas que busquem incluir e abrir as portas das universidades para determinados grupos que, em termos numéricos, encontrem-se em menor proporção nessas instituições de ensino. No assunto das cotas universitárias, percebeu-se que o governo incentivou o estabelecimento de cotas nos vestibulares, todavia, preferiu deixar amplamente a cargo das universidades a deliberação sobre os parâmetros que tal ação afirmativa assumiria dentro da instituição, afirmando, portanto, o princípio da autonomia universitária.

Conclui-se que o cenário brasileiro ainda precisa compreender que os diálogos institucionais representam uma das formas mais legítimas, harmônicas e eficazes de se deliberar quanto aos assuntos que envolvem uma grande polêmica. No trato institucional das cotas universitárias, constatou-se uma possível vulnerabilidade ou, mesmo, a ausência de uma real interação dialógica entre os poderes do Estado e as universidades. Destacase aqui que, neste tema, tanto a irrestrita autonomia universitária quanto a supremacia judicial do STF não representam o melhor caminho para o deslinde da controvérsia. 
O sistema de cotas é detentor de uma preocupação política, pois é capaz de influenciar não apenas o rumo cultural de uma nação, mas também o seu equilíbrio jurídico, principalmente. As cotas traduzem um planejamento de longo prazo capaz de promover justas mudanças no cenário brasileiro não apenas educacional, e sim, em sua plenitude. Sendo assim, entende-se que enquanto não houver uma diretriz nacional coerente que oriente a criação de critérios, conceitos e argumentos, em uma dinâmica de deliberação que valorize os diálogos institucionais, o sistema de cotas vigente poderá ser pouco eficaz na promoção da igualdade de condições e de oportunidades entre os cidadãos.

\section{REFERÊNCIAS}

ALEXY, Robert. Teoria dos direitos fundamentais. Tradução Virgílio Afonso da Silva. São Paulo: Malheiros, 2008.

ÁVILA, Humberto. A distinção entre princípios e regras e a redefinição do dever de proporcionalidade. Revista Diálogo Jurídico, Salvador, v. 1, n. 4, jul. 2001. Disponível em: $<$ http://www.direitopublico.com.br>. Acessado em: 25 de fevereiro de 2011.

BARROSO, Luís Roberto. Os princípios da razoabilidade e da proporcionalidade no direito constitucional. Cadernos de Direito Constitucional e Ciência Política, São Paulo: Revista dos Tribunais, ano 6, n. 23, p. 65-78, abr./jun. 1998.

. O direito constitucional e a efetividade de suas normas. 8. ed. Rio de Janeiro: Renovar, 2006. . Racismo e papel da universidade. In: Jornal O Globo. 28/02/03. Rio de Janeiro.

BELCHIOR, Douglas Elias. Direito de branco, direito de negro, direitos humanos. Cartilha Intensivão de Cidadania da Educafro. Região Bragantina e Campinas: Coordenação Nacional da Educafro, abril 2008.

BOBBIO, Norberto. Teoria geral da política: a filosofia política e as lições dos clássicos. Rio de Janeiro: Campus, 2000.

BOLONHA, Carlos. EISENBERG, José. RANGEL, Henrique. Problemas Institucionais do Constitucionalismo Contemporâneo. Revista de Direitos Fundamentais \& Justiça, v. 17, 288-309, 2011.

CAPLAN, Lincoln. Up against the law: affirmative action and the Supreme Court. New York: The Twentieth Century Fund Press, 1997.

COMPARATO, Fábio Konder. Igualdade, desigualdades. Revista Trimestral de Direito Público. São Paulo, n. 1, p. 69-78, 1993. . A Afirmação Histórica dos Direitos Humanos. 2. ed. São Paulo: Saraiva, 2001.

COSTA, Sérgio. Dois Atlânticos: teoria social, anti-racismo, cosmopolitismo. Belo Horizonte: Editora UFMG, 2006.

DALLARI, Dalmo de Abreu. Elementos da Teoria Geral do Estado. 25. ed. São Paulo. DWORKIN, Ronald. Uma questão de princípios, parte cinco "A discriminação inversa". Martins fontes, 2006. 
2005a.

. Levando os direitos a sério, parte nove "A discriminação compensatória". Martins fontes,

. A virtude soberana. Martins Fontes. São Paulo, 2005b.

FISS, Owen. Affirmative Action: An Answer to Discrimination? American Enterprise Institute Roundtable, 1975.

. Affirmative Action as a Strategy of Justice, Philosophy \& Public Policy 1997.

1986.

. Racial Discrimination. Encyclopedia of the American Constitution 1500. Leonard Levy,

FREYRE, Gilberto. Casa-grande e senzala. São Paulo: Global, 2005.

GOMES, Joaquim B. Barbosa; DA SILVA, Fernanda Duarte Lopes Lucas. As ações afirmativas e os processos de promoção da Igualdade efetiva. Série Cadernos do CEJ. p. 86-153. Disponível em:

< http://w3.ufsm.br/afirme/ARTIGOS/variados/var02.pdf> . Acessado em: 25 de fevereiro de 2012.

. A recepção do instituto da ação afirmativa pelo direito constitucional brasileiro. Revista de Informação Legislativa. Brasília: Senado, a.38 n. 151, p.129-152, jul./set. 2001. Disponível em: < http://www.adami.adv.br/artigos/19.pdf>. Acessado em: 25 de fevereiro de 2012.

- Ação afirmativa e princípio constitucional da igualdade: o direito como instrumento de transformação social. A experiência dos EUA. Rio de Janeiro: Renovar, 2001.

. Discriminação racial e o princípio da igualdade. Revista de Informação Legislativa. Brasília: Senado Federal, ano 36, n. 142, p. 307-323, 1999.

GOODIN, Robert E. The Theory of Institutional Design. Cambridge: Press Syndicate of the Univesity of Cambridge, 1996.

INSTITUTO BRASILEIRO DE GEOGRAFIA E ESTATÍSTICA. Síntese de Indicadores Sociais Uma Análise das Condições de Vida da População Brasileira 2010.

IKAWA, Daniela. Direito às ações afirmativas em universidades brasileiras. In: SARMENTO, Daniel; PIOVESAN, Flávia; IKAWA, Daniela. Igualdade, diferença e direitos humanos. Rio de Janeiro: Lumen Juris, 2008a.

. Ações Afirmativas em Universidades. Rio de Janeiro: Lúmen Júris, 2008b.

KAMEL, Ali. Não somos racistas: uma reação aos que querem nos transformar numa nação bicolor. Rio de Janeiro: Nova Fronteira, 2006.

KAUFMANN, Roberta Fragoso Menezes. As diversas cores do Brasil: a inconstitucionalidade de programas afirmativos em que raça seja o único critério levado em consideração. Revista de Direito Constitucional e Internacional, n. 60, 2007.

LENZA, Pedro. Direito Constitucional Esquematizado. p. 303. 14. ed. São Paulo. Saraiva. 2010.

LUSTOSA, Isabel. Excesso de cor. In: FRY, Peter et al. (Org.). Divisões perigosas: políticas raciais no Brasil contemporâneo. Rio de Janeiro: Civilização Brasileira, 2007.

MELLO, Celso Antônio Bandeira de. O Conteúdo Jurídico do Princípio da Igualdade. 3. ed. São Paulo: Malheiros, 1993.

MENDES, Conrado Hübner. Direitos fundamentais, separação de poderes e deliberação. 2008. $224 \mathrm{f}$.

Tese (Doutorado em Ciência Política) - Faculdade de Filosofia, Letras e Ciências Humanas, 
Universidade de São Paulo, São Paulo. 2008. Disponível em: < http://www.teses.usp.br/teses/ disponiveis/8/8131/tde-05122008-162952/pt-br.php > . Acessado em: 25 de fevereiro de 2012.

MENDES, Gilmar. O princípio da proporcionalidade na jurisprudência do Supremo Tribunal Federal: novas leituras. Revista Diálogo Jurídico, Salvador, ano 1, v. 1, n. 5, p. 18-19, ago. 2001.

MUNANGA, Kabengele. Uma abordagem conceitual das noções de raça, racismo, identidade e etnia. Palestra proferida no $3^{\circ}$ Seminário Nacional Relações Raciais e Educação-PENESB-RJ, 05/11/03. . Políticas de ação afirmativa em benefício da população negra no Brasil: um ponto de vista em defesa das cotas. Texto apresentado na IX Semana de Ciências Sociais da UFG, de 4 a 8 de novembro de 2002, a convite do Projeto Passagem do Meio: Qualificação de Alunos(as) Negros(as) de Graduação para Pesquisa Acadêmica na UFG/LPP-UERJ/Fundação Ford.

PIOVESAN, Flávia. Ações afirmativas da perspectiva dos direitos humanos. Cadernos de PesquisaFundação Carlos Chagas, São Paulo, v. 35, n. 124, p. 43-55, jan./abr. 2005.

RIBEIRO DE SOUZA, Hilda Maria Montes. A experiência das cotas na UERJ - política de permanência. Texto produzido pela diretora do departamento de desenvolvimento acadêmico e projetos de inovação. Publicado em: 04 de maio de 2010.

ROCHA, Cármen Lúcia Antunes. Ação Afirmativa - O Conteúdo Democrático do Princípio da Igualdade Jurídica. Revista Trimestral de Direito Público, n. 15/85.

SARMENTO, Daniel. A igualdade étnico-racial no direito constitucional brasileiro: discriminação "de facto", teoria do impacto desproporcional e ação afirmativa. Livres e iguais. Rio de Janeiro: Lumen Juris, 2006.

SILVA, Cecília de Almeida; MOURA, Francisco; BERMAN, José Guilherme; VIEIRA, José Ribas; TAVARES, Rodrigo de Souza; VALLE, Vanice Regina Lírio do. Diálogos Institucionais e Ativismo. Juruá Editora. 2010.

SILVA, José Afonso da. Curso de direito constitucional positivo. 34. ed. São Paulo: Malheiros, 2011. SILVA, Virgílio Afonso da. O proporcional e razoável. Revista dos Tribunais, n. 798, p. 23-50, 2002. 